\title{
Evaluation of air-particle abrasion of Y-TZP with different particles using microstructural analysis
}

\author{
Turp, V ; Sen, D ; Tuncelli, B ; Goller, G ; Özcan, M
}

\begin{abstract}
BACKGROUND: This study evaluated the effect of air-particle abrasion with different particle sizes on the surface roughness and phase transformation of yttria-stabilized tetragonal zirconia ceramics (Y-TZP). METHODS: Eighty-four Y-TZP discs of $15 \mathrm{~mm}$ diameter and $1.0 \mathrm{~mm}$ thickness were fabricated. The samples were divided into four groups $(\mathrm{n}=21)$ : (1) air-particle abrasion with $30 \mu \mathrm{m}$ CoJet sand blast coating agent (CoJet, 3M ESPE); (2) $50 \mu \mathrm{m} \mathrm{Al} 2 \mathrm{O} 3$ particles; (3) $110 \mu \mathrm{m}$ Al2O3 particles; and (4) $250 \mu \mathrm{m} \mathrm{Al} 2 \mathrm{O} 3$ particles. Each group was further divided into three subgroups each $(\mathrm{n}=7)$ and treated for 5 seconds, 15 seconds and 30 seconds. Mean surface roughness was determined using a profilometer. The surfaces were analysed with a scanning electron microscope. XRD analysis was employed and the relative amount of the monoclinic phase was calculated. The results were statistically analysed by two-way analysis of variance (ANOVA, p < 0.05). RESULTS: Air-particle abrasion with $250 \mu \mathrm{m} \mathrm{Al} 2 \mathrm{O} 3$ particles for 30 seconds had the highest surface roughness $(\mathrm{p}<0.001)$ and a significantly higher amount of monoclinic phase compared to air-particle abrasion with $30 \mu \mathrm{m}, 50 \mu \mathrm{m}$ and $110 \mu \mathrm{m}$ particles $(p<0.001)$. CONCLUSIONS: Duration and particle size of air-particle abrasion affects the roughness and phase transformation of Y-TZP. Longer treatment times with larger particles may result in degradation of material.
\end{abstract}

DOI: https://doi.org/10.1111/adj.12065

Posted at the Zurich Open Repository and Archive, University of Zurich ZORA URL: https://doi.org/10.5167/uzh-89900

Journal Article

Accepted Version

Originally published at:

Turp, V; Sen, D; Tuncelli, B; Goller, G; Özcan, M (2013). Evaluation of air-particle abrasion of Y-TZP with different particles using microstructural analysis. Australian Dental Journal, 58(2):183-191.

DOI: https://doi.org/10.1111/adj.12065 
Effect of particle size and deposition duration of air-particle abrasion on the surface properties and microstructure of zirconia

\section{Turp, ${ }^{*}$ D. Sen, ${ }^{*}$ B. Tuncelli, ${ }^{*}$ G. Goller, ${ }^{\dagger}$ M. Özcan ${ }^{\ddagger}$}

*Istanbul University, Faculty of Dentistry, Department of Prosthodontics, Istanbul, Turkey.

${ }^{\dagger}$ Istanbul Technical University, Department of Metallurgical Materials and Engineering, Istanbul, Turkey.

¥University of Zurich, Dental Materials Unit, Center for Dental and Oral Medicine, Clinic for Fixed and Removable Prosthodontics and Dental Materials Science, Zurich, Switzerland.

Short Title: Air-particle abrasion effect on zirconia

Address for correspondance:

Dr. Volkan Turp Istanbul University

Faculty of Dentistry

Department of Prosthodontics

34098 Fatih

Istanbul, Turkey

Email:vturp@istanbul.edu.tr 


\section{ABSTRACT}

Background: This study evaluated the effect of particle size and deposition duration of air-particle abrasion on the surface properties and microstructure of zirconia.

Methods: Zirconia discs ( $\mathrm{N}=84)$ (diameter: $15 \mathrm{~mm}$, thickness: $1 \mathrm{~mm}$ ) (Cercon, Degudent) were polished and randomly divided into 4 groups $(n=21)$. Specimens were subjected to air-particle abrasion with a) 30 $\mu \mathrm{m} \mathrm{SiO}_{2}$ (CoJet, 3M ESPE), b) $50 \mu \mathrm{m} \mathrm{Al} \mathrm{O}_{3}$ particles, c) $110 \mu \mathrm{m} \mathrm{Al} \mathrm{O}_{3}$ particles and d) $250 \mu \mathrm{m} \mathrm{Al}_{2} \mathrm{O}_{3}$ particles for a duration of 5,15 and 30 seconds ( $n=7$ per subgroup). Surface roughness was measured using a 3D profilometer and the relative amount of monoclinic phase was calculated using XRD. Specimen surfaces were also analyzed under SEM. Data were statistically analyzed by 2-way ANOVA and Tukey`s test (alpha $=0.05)$.

Results: Air-particle abrasion with $30 \mu \mathrm{m} \mathrm{SiO} 2$ created significantly less surface roughness $(0.57 \pm 0.04$ $0.69 \pm 0.1 \mu \mathrm{m})$ than those of other particle types at all deposition durations $(p<0.001)$. The highest roughness was observed with $250 \mu \mathrm{m} \mathrm{Al}_{2} \mathrm{O}_{3}$ particles after 30 seconds deposition $(1.16 \pm 0.2 \mu \mathrm{m})$ $(p<0.001)$. The highest amount of monoclinical phase was observed with $250 \mu \mathrm{m} \mathrm{Al}_{2} \mathrm{O}_{3}$ particles after 30 seconds $(16.43 \%)$ compared to other groups $(9.11-15.6 \%)(p<0.001)$.

Conclusions: Increase in particle size from 30 to $250 \mu \mathrm{m}$ and deposition duration from 5 to 30 seconds during air-particle abrasion, enhances surface roughness and monoclinical phase of zirconia.

Keywords: Aging, air-particle abrasion, Y-TZP, XRD analysis, zirconia, surface roughness 


\section{INTRODUCTION}

High aesthetic demands of patients and biocompatibility requirements have increased the use of allceramic systems in dentistry. A major problem with all-ceramic systems is the low fracture resistance. Yttria-stabilized tetragonal zirconia polycrystal (hereon: zirconia) is employed as framework materials for fixed dental prosthesis (FDP) in prosthodontics or as implant material due to their high strength and toughness. ${ }^{1}$ Zirconia frameworks for FDPs are fabricated using the CAD/CAM systems as a standard routine. $^{2}$

Pure zirconia has a monoclinic crystal structure at room temperature and transitions to tetragonal and cubic phase at increasing temperatures. ${ }^{3}$ The volume expansion caused from cubic to tetragonal and tetragonal to monoclinic phase transformation induces high stresses that may cause pure zirconia to crack upon cooling from high temperatures. Several different oxides such as magnesium oxide, yttrium oxide, calcium oxide, and cerium oxide are added to zirconia to stabilize the tetragonal and/or cubic phases. Among all phases, tetragonal phase is metastable. Compared to the other dental ceramics, zirconia has superior mechanical properties due to the transformation toughening mechanism. ${ }^{4}$ When sufficient quantity of the metastable tetragonal phase is present, then an applied stress, magnified by the stress concentration at a crack tip, can cause the tetragonal phase to convert to monoclinic. ${ }^{4}$ This results in a volume expansion. Phase transformation can then put the crack into compression, retarding its growth, and enhancing the fracture toughness. This mechanism is known as transformation toughening, and significantly extends the reliability and lifetime of products made with stabilized zirconia.,

During laboratory or chairside procedures such as grinding, polishing or surface conditioning with abrasives, commonly performed by dental technicians and clinicians, internal stresses may cause phase transformation in the material. Air-particle abrasion is reported to be a requirement in order to achieve sufficient adhesion between the adhesive resin cements and zirconia ceramics. ${ }^{5-8}$ Air-abrasion systems rely on the deposition of different particle types and sizes ranging between 30 to $250 \mu \mathrm{m} .^{9,10}$ The abrasion process removes the uppermost contaminated loose layers and the roughened surface provides some level of mechanical retention with the adhesive resin cement. ${ }^{9,10}$ However, the knowledge as to whether using large or small particle size to increase resin bond to high-strength ceramics of different 
microstructures and chemical compositions is limited. ${ }^{11,12}$ Furthermore, to the authors ${ }^{\prime}$ best knowledge the possible effect on the transformation change as a function of deposition duration has not been studied.

The objectives of this study therefore, were to evaluate the effect of particle size and deposition duration of air-particle abrasion on the surface properties and microstructure of zirconia. The null hypothesis tested was that particle type and deposition duration would not affect the surface morphology, roughness and phase transformation of zirconia.

\section{MATERIALS AND METHODS}

\section{Specimen preparation}

Zirconia discs $(\mathrm{N}=84)$ (diameter: $15 \mathrm{~mm}$, thickness: $1 \mathrm{~mm}$ ) were fabricated from non-HIPPED Cercon blocks (Cercon, Degudent, Hanau, Germany). They were sintered to full density in a furnace, according to the manufacturer's instructions and polished under water to the final thickness of $1 \pm 0.13 \mathrm{~mm}$ with 320 -, 400-, 600-, and 1200-grit SiC papers (Struers, Ballerup, Denmark) using a polishing machine (LaboPol-5, Struers, Ballerup, Denmark).

Zirconia discs were then randomly divided into 4 groups $(n=21)$. Specimens were subjected to airparticle abrasion with a) $30 \mu \mathrm{m} \mathrm{SiO}{ }_{2}$ (CoJet, $3 \mathrm{M}$ ESPE, Seefeld, Germany), b) $50 \mu \mathrm{m} \mathrm{Al}_{2} \mathrm{O}_{3}$ particles (Korox, Bego, Bremen, Germany), c) $110 \mu \mathrm{m} \mathrm{Al}_{2} \mathrm{O}_{3}$ particles (Korox) and d) $250 \mu \mathrm{m} \mathrm{Al} \mathrm{O}_{3}$ particles (Korox) for a duration of 5,15 and 30 seconds ( $n=7$ per subgroup) at 2 bar pressure from a distance of approximately $10 \mathrm{~mm}$ (Easyblast, BEGO, Bremen, Germany).

\section{Surface roughness measurement}

After air-abrasion protocols, surface roughness of zirconia specimens were measured using a 3D optical profilometer (Veeco NT1100, Veeco, New York, USA). Non-contact, white-light vertical interferometer was used to measure the roughness of the assessed profile $\left(R_{a}\right)$ using following parameters: magnification: 5.12x, sampling: $1.64 \mu \mathrm{m}$, array size: $736 \times 480$. Three measurements were made with a travelling distance of $2 \mathrm{~mm}$ across the treated surface of the specimens, and the mean value was calculated for each group. 3D images were captured using the software of the equipment (Wyko Vision 32, New York, USA). 


\section{X-Ray Diffraction and SEM analysis}

The relative amount of monoclinic phase of zirconia as a function of particle type and deposition duration was calculated using X-ray diffraction analysis (X'pert Pro PANalytical, Almelo, The Netherlands). The calculations were based on the method of Garvie and Nicholson, according to the formula: ${ }^{13}$

$X_{m}=\left[I_{m}(-111)+I_{m}(111)\right] /\left[I_{m}(-111)+I_{m}(111)+I_{t}(101)\right]$

where $X_{m}$ is the mass fraction of monoclinic phase, $I_{m}(-111)$ is the intensity of monoclinic peak at $28.2^{\circ}$, $I_{m}(111)$ is the intensity of monoclinic peak at $31.5^{\circ}$ and $\mathrm{I}_{\mathrm{t}}(101)$ is the intensity of monoclinic peak at $30.2^{\circ}$.

Monoclinic phase volume percentage $\left(V_{m}\right)$ was calculated using formula of Toraya et al. ${ }^{14}$

$V_{m}=1.311 X_{m} /\left(1+0.311 X_{m}\right)$

where $V_{m}$ is the monoclinic phase volume percentage and $X_{m}$ is the mass fraction of monoclinic phase.

The surfaces of the 30 second treated specimens were further evaluated using Scanning Electron Microscope (SEM, JSM 7000F, JEOL, Japan) at x700 magnification.

\section{Statistical analysis}

Statistical analysis was performed using the software Statistix 8.0 for Windows (Analytical Software Inc, Tallahassee, FL, USA). The surface roughness data $(\mu \mathrm{m})$ and relative amount of the monoclinic phase were submitted to two-way analysis of variance (2-way ANOVA) separately with the particle types (4 levels; $30,50,110,250 \mu \mathrm{m}$ particles) and deposition durations ( 3 levels; $5,15,30$ seconds) as independent variables. Multiple comparisons were made using Tukey`s test. $P$ values less than 0.05 were considered to be statistically significant in all tests.

\section{Results}

Particle type $(p<0.001)$ and air-abrasion deposition duration $(p<0.001)$ had a significant effect on the surface roughness of zirconia. Interaction terms were also significant $(p<0.001)$.

Except $30 \mu \mathrm{m} \mathrm{\textrm {SiO } _ { 2 }}$ group, there was no statistically significant difference in surface roughness between subgroups after 5 seconds of deposition. As the deposition duration increased, the mean roughness values increased significantly $(p<0.001)($ Table 1$)$. 
Air-particle abrasion with $30 \mu \mathrm{m} \mathrm{SiO}{ }_{2}$ created significantly less surface roughness $(0.57 \pm 0.04-0.69 \pm 0.1$ $\mu \mathrm{m})$ than those of other particle types at all deposition durations $(p<0.001)$. There was no significant difference between 5 and 15 seconds of $30 \mu \mathrm{m} \mathrm{SiO}_{2}$ deposition $(p>0.001)$ but 30 seconds subgroup created significantly higher roughness $(p<0.001)$.

The highest roughness was observed with $250 \mu \mathrm{m} \mathrm{Al}_{2} \mathrm{O}_{3}$ particles after 30 seconds deposition $(1.16 \pm 0.2$ $\mu \mathrm{m})(\mathrm{p}<0.001)$.

Particle type $(p<0.001)$ and air-abrasion deposition duration $(p<0.001)$ had a significant effect on the relative amount of monoclinical phase. Interaction terms were also significant $(p<0.001)$.

The highest relative amount of monoclinical phase was observed with $250 \mu \mathrm{m} \mathrm{Al} \underline{2}_{3}$ particles after 30 seconds $(16.43 \pm 0.33 \%)$ compared to other groups $(p<0.001)$ (Table 2). Deposition duration of $30 \mu \mathrm{m} \mathrm{SiO}_{2}$ did not affect the monoclinic phase significantly ( $p>0.001)$. For the 50 and $110 \mu \mathrm{m}$ particles, 30 seconds of deposition increased the monoclinic phase significantly compared to 5 and 15 seconds $(p<0.001)$. The XRD diagrams for each group are presented in Figs. 1a-d. Tetragonal and monoclinic peaks can be observed in the diagrams.

The 3D profilometry images displayed an increase in surface roughness and irregularities of the surface with the increase in the particle size and deposition duration but the traces of hard-machining were not completely removed even after 30 seconds (Figs. 2a-d). However, it can be observed that grooves and valleys on the surface are flattened as the application duration increased.

SEM images indicated grooves and scratches after 30 seconds of deposition with all particle sizes (Figs. 3a-d). Major qualitative differences were not observed in SEM imagery, hard machining traces were present in all groups.

\section{DISCUSSION}

Zirconia ceramics seem to be able to withstand high chewing forces but establishing adhesion of the luting cement to this ceramic is a critical issue for their clinical success. ${ }^{5,6,15-17}$ Although there is not a specific cementation protocol supported by clinical evidence for zirconia FDPs, ${ }^{7,18}$ the recommended approach is the use of resin cements in combination with surface treatments..$^{19}$ Unfortunately, zirconia is affected by 
several conditioning methods applied to its surface during common stages of manufacturing and clinical adjustment of the restoration, such as hard-machining, grinding and air-particle abrasion. ${ }^{20}$ Among these, air-particle abrasion has been reported to be a prerequisite for achieving sufficient bond strength between zirconia and resin cement. $6,8,21$

Air-abrasion systems are typically based on deposition of particles ranging between 30 to $250 \mu \mathrm{m}$ on the material's surface under pressure. ${ }^{10,22}$ The increase in roughness also forms a larger surface area for the retention of the resin cement. However, there is limited knowledge as to whether micromechanical retention using large or small particle size results in degradation of the mechanical properties of zirconia. ${ }^{21}$ Therefore, this study was undertaken to evaluate the effect of particle size and deposition duration of airparticle abrasion on the surface properties and microstructure of zirconia. Since the surface roughness results and the relative amount of monoclinical phase varied as a function of particle size and depostion duration, the null hypothesis tested was rejected.

Air-particle abrasion is in fact a gentle conditioning process compared to other surface treatments. ${ }^{16}$ The $^{-1}$ abrasion and heat produced by air-particle abrasion is considerably less compared to hard machining and grinding and it has been reported in several studies that the strength of the material could even increase after the air-abrasion process. ${ }^{22,23}$ In this study, as the particle size and application duration increased, the significant increase in monoclinic phase was observed. ${ }^{20,23}$ This may be resulting from an excess $t-m$ transformation on the surface of the specimens. Hence, it can be anticipated that air-particle abrasion may lose its positive effect due to increase in duration of application and particle size. In principle, air-particle abrasion is used to clean and achieve micromechanical retention on the ceramic surface. However, the application duration or the particle size may change depending on the clinical objectives. For this reason, in this study 5,15 and 30 seconds of deposition was chosen. Among specimens treated for 5 seconds, 30 $\mu \mathrm{m} \mathrm{SiO}_{2}$ group showed statistically less surface roughness and monoclinical phase compared to those of other 50,110 and $250 \mu \mathrm{m} \mathrm{Al}_{2} \mathrm{O}_{3}$. The so-called CoJet sand is basically ordinary alumina particles coated with silica using the sol-gel technology. With all particle types, 5 seconds of deposition seem to create the least damage on zirconia. Yet, considering the hard surface of zirconia, one can argue whether 5 seconds would be sufficient to achieve a clean, microretentive surface for sufficient adhesion. Also, surface area of 
the restoration dictates the necessity for longer deposition duration. Nevertheless, as the duration increased, significant differences in surface roughness were observed depending on the particle size. With the increase in particle size increased, the surface irregularities also increased, supported by the profilometry images and measurements. However, a flattening of surface was observed in the topographic profilometry images while the surface roughness was increased. According to this result it can be speculated that although wide valleys and grooves are leveled by air-particle abrasion, roughness increases on the smaller areas where measurements are read.

The increase in monoclinic phase was parallel with surface roughness measurements in all groups, being more prominent for 110 and $250 \mu \mathrm{m} \mathrm{Al}_{2} \mathrm{O}_{3}$. This phenomenon was attributed to tetragonal to monoclinic phase transformation on the zirconia surface, resulting in grain push-out and thereby, increased surface roughness. ${ }^{11}$ Excessive tetragonal to monoclinic phase transformation may affect the mechanical properties of the zirconia negatively and result in degradation of this ceramic. ${ }^{11}$ Kosmac et al. observed zirconia layers after air-particle abrasion with $110 \mu \mathrm{m}$ particles. They reported the formation of a thin compressive surface layer and surface cracks that do not exceed this zirconia layer. They stated that the thickness of this layer is the similar to the size of an average zirconia grain, and it even increases the strength of the material by initiating transformation when confronted with stress. ${ }^{20,23}$ The changes in the compressive surface layer may be important as it may be affected by longer deposition durations. The findings of this study support this phenomenon.

According to the current information, the maximum acceptable amount of monoclinic phase in zirconia is 25 per cent. ${ }^{24,25}$ The amount of monoclinic phase after $250 \mu \mathrm{m} \mathrm{Al} \mathrm{O}_{3}$ particle deposition for 15 and 30 seconds $(15.63 \%$ and $16.43 \%$, respectively) did not exceed this limit. Also, SEM images verified that the grooves and traces of hard-machining were not completely removed after 30 seconds of air-particle abrasion, regardless of the grain size. In a previous study, it was reported that air-particle abrasion with 50 $\mu \mathrm{m} \mathrm{Al}_{2} \mathrm{O}_{3}$ increased the strength of zirconia by removing the weak grains and grinding traces, whereas 120 $\mu \mathrm{m} \mathrm{Al}_{2} \mathrm{O}_{3}$ weakened this ceramic, as the latter created new surface flaws. ${ }^{26}$ Sato et al. used $125-\mu \mathrm{m}$ silicium carbide and $70-\mu \mathrm{m}$ alumina $\mathrm{Al}_{2} \mathrm{O}_{3}$ for air-particle abrasion and reported that biaxial flexural strength of zirconia increased by the stress-induced transformation with high monoclinic phase content. ${ }^{27}$ 
However, they also reported that excess phase transformation that took place after silicium carbide airparticle abrasion decreased the biaxial flexural strength. ${ }^{27}$ Thus, future studies should not only report on the particle size used but also the deposition duration and pressure should be mentioned as it may relate to the formation of a better compressive layer.

Until it is clinically proven whether air-abrasion contributes to degradation of zirconia, clinicians should apply air-particle abrasion as short as possible and use preferably particles with less sharp morphologies. Further studies are recommended look at the longer deposition durations of air-particle abrasion on microstructure and mechanical properties of zirconia.

\section{CONCLUSIONS}

The increase in particle size and deposition duration during air-abrasion protocols enhanced the surface roughness and monoclinic phase transformation of the tested zirconia.

\section{Disclosure}

The authors declare that they have no conflict of interests. 


\section{REFERENCES}

1. Filser F, Kocher $P$, Weibel F, Lüthy H, Schärer $P$, Gauckler LJ. Reliability and strength of all-ceramic dental restorations fabricated by direct ceramic machining (DCM). Int J Compt Dent 2001;4:89-106.

2. Miyazaki T, Hotta $\mathrm{Y}$, Kunii J, Fujiwara T. Current status and future prospects of a dental CAD/CAM system used in crown-bridge restorations. Dent Jpn 2007;43:189-194.

3. Chevalier J. What future for zirconia as a biomaterial? Biomaterials 2006;27:535-543.

4. Piconi C, Maccauro G. Zirconia as a ceramic biomaterial. Biomaterials 1999;20:1-25.

5. Blatz MB, Sadan A, Kern M. Resin-ceramic bonding: a review of the literature. J Prosthet Dent 2003;89:268-274.

6. Özcan M, Vallittu PK. Effect of surface conditioning methods on the bond strength of luting cement to ceramics. Dent Mater 2003;19:725-731.

7. Edelhoff $D$, Özcan M. To what extent does the longevity of fixed dental prostheses depend on the function of the cement? Clin Oral Implants Res 2007;18:193-204.

8. Özcan M, Kerkdijk S, Valandro LF. Comparison of resin cement adhesion to Y-TZP ceramic following manufacturers' instructions of the cements only. Clin Oral Investig 2008;12:279-282.

9. Özcan M, Pfeiffer P, Nergiz I. A brief history and current status of metal/ceramic surface conditioning concepts for resin bonding in dentistry. Quintessence Int 1998;29:713-724.

10. Özcan M. Evaluation of alternative intraoral repair techniques for fractured ceramic-fused-to-metal restorations. J Oral Rehabil 2003;30:194-203.

11. Guazzato M, Quach L, Albakry M, Swain MV. Influence of surface and heat treatments on the flexural strength of Y-TZP dental ceramics. J Dent 2005;33:9-18.

12. Deville S, Chevalier J, Gremillard L. Influence of surface finish and residual stresses on the ageing sensitivity of biomedical grade zirconia. Biomaterials 2006;27:2186-2192.

13. Garvie RC, Nicholson PS. Phase analysis in zirconia systems. J Am Ceram Soc 1972;55:303-330.

14. Toraya H, Yoshimura M, Sōmiya S. Calibration curve for quantitative analysis of the monoclinictetragonal $\mathrm{ZrO}_{2}$ system by X-ray diffraction. J Am Ceram Soc 1984;67:119-121. 
15. Koutayas $\mathrm{O}$, Vagkopoulou T, Pelekanos S, Koidis P, Strub JR. Zirconia in dentistry Part 2. Evidencebased clinical breakthrough. Eur J Esthet Dent 2009;4:348-380.

16. Aboushelib MN, Feilzer AJ, Kleverlaan CJ. Bonding to zirconia using a new surface treatment. J Prosthodont 2010;19:340-346.

17. Bachhav VC, Aras MA. Zirconia-based fixed partial dentures: a clinical review. Quintessence Int 2011;42:173-182.

18. Cavalcanti AN, Foxton RM, Watson TF, Oliveira MT, Giannini M, Marchi GM. Y-TZP ceramics: key concepts for clinical application. Oper Dent 2009;34:344-351.

19. Mizrahi B. The anterior all-ceramic crown: a rationale for the choice of ceramic and cement. $\mathrm{Br}$ Dent $\mathrm{J}$ $2008 ; 205: 251-255$.

20. Kosmac T, Oblak C, Jevnikar P, Funduk N, Marion L. The effect of surface grinding and sandblasting on flexural strength and reliability of Y-TZP zirconia ceramic. Dent Mater 1999;15:426-433.

21. Amaral R, Özcan M, Bottino MA, Valandro LF. Microtensile bond strength of a resin cement to glass infiltrated zirconia-reinforced ceramic: the effect of surface conditioning. Dent Mater 2006;22:283-290.

22. Denry IL, Holloway JA. Microstructural and crystallographic surface changes after grinding zirconiabased dental ceramics. J Biomed Mater Res Part B: Appl Biomater 2006;76:440-448.

23. Kosmac T, Oblac C, Jevnikar P, Funduk N, Marion L. Strength and reliability of surface treated Y-TZP dental ceramics. J Biomed Mater Res 2000;53:304-313.

24. ISO Standard 13356:2008 Implants for surgery -- Ceramic materials based on yttria-stabilized tetragonal zirconia (Y-TZP)

25. Lughi V, Sergo V. Low temperature degradation -aging- of zirconia: A critical review of the relevant aspects in dentistry. Dent Mater 2010;26:807-820.

26. Wang $\mathrm{H}$, Aboushelib MN, Feilzer AJ. Strength influencing variables on CAD/CAM zirconia frameworks. Dent Mater 2008;24:633-638.

27. Sato H, Yamada K, Pezzotti G, Nawa M, Ban S. Mechanical properties of dental zirconia ceramics changed with sandblasting and heat treatment. Dent Mater J 2008;27:408-414. 


\section{Captions to tables and figures:}

\section{Tables:}

Table 1. Mean surface roughness $(\mathrm{Ra}, \mu \mathrm{m})$ and standard deviations of zirconia specimens as a function of particle type and deposition duration. Same superscript capital letters indicate no significant difference in the same row, and small letters in the same column $(p<0.05)$

Table 2. Relative amount of monoclinical phase (\%) according to XRD measurements. Same superscript capital letters indicate no significant difference in the same row, and small letters in the same column $(p<0.05)$

\section{Figures:}

Figs. 1a-d XRD diagrams of zirconia specimens after deposition of a) $30 \mu \mathrm{m} \mathrm{SiO}$, b) $\left.50 \mu \mathrm{m} \mathrm{Al}_{2} \mathrm{O}_{3}, \mathbf{c}\right) 110$ $\mu \mathrm{m} \mathrm{Al}_{2} \mathrm{O}_{3}$ and d) $250 \mu \mathrm{m} \mathrm{Al} \mathrm{O}_{3}$ for 5,15 and 30 seconds. Note the differences in $\mathrm{T}$ and $\mathrm{M}$ peaks as the application duration changes.

Figs. 2a-d 3D profilometry images of zirconia specimens after deposition of a) $\left.30 \mu \mathrm{m} \mathbf{S i O}_{2}, \mathbf{b}\right) 50 \mu \mathrm{m}$ $\mathrm{Al}_{2} \mathrm{O}_{3}$, c) $110 \mu \mathrm{m} \mathrm{Al} \mathrm{O}_{3}$ and d) $250 \mu \mathrm{m} \mathrm{Al}_{2} \mathrm{O}_{3}$ for 5,15 and 30 seconds. Note that the hard-milling traces were not completely removed in all groups.

Figs. 3a-d SEM images (x700) of zirconia specimens after deposition of a) $30 \mu \mathrm{m} \mathrm{SiO}$, b) $\left.50 \mu \mathrm{m} \mathrm{Al}_{2} \mathrm{O}_{3}, \mathbf{c}\right)$ $110 \mu \mathrm{m} \mathrm{Al}_{2} \mathrm{O}_{3}$ and d) $250 \mu \mathrm{m} \mathrm{Al}_{2} \mathrm{O}_{3}$ for 30 seconds. Note that the hard-milling traces were not completely removed in all groups. 


\section{Tables}

\begin{tabular}{|c|c|c|c|}
\hline & 5 seconds & 15 seconds & 30 seconds \\
\hline $30 \mu \mathrm{m} \mathrm{SiO}$ & $0.57 \pm 0.04^{\mathrm{A}, \mathrm{a}}$ & $0.62 \pm 0.12^{A, a}$ & $0.69 \pm 0.11^{\mathrm{B}, \mathrm{a}}$ \\
\hline $50 \mu \mathrm{m} \mathrm{Al} \mathrm{O}_{3}$ & $0.80 \pm 0.13^{A, b}$ & $0.87 \pm 0.14^{\mathrm{B}, \mathrm{b}}$ & $0.94 \pm 0.18^{\mathrm{C}, \mathrm{b}}$ \\
\hline $110 \mu \mathrm{m} \mathrm{Al} \mathrm{O}_{3}$ & $0.82 \pm 0.14^{\mathrm{A}, \mathrm{b}}$ & $0.91 \pm 0.21^{\mathrm{B}, \mathrm{C}}$ & $1.10 \pm 0.11^{\mathrm{B}, \mathrm{C}}$ \\
\hline $250 \mu \mathrm{m} \mathrm{Al} \mathrm{O}_{3}$ & $0.83 \pm 0.16^{\mathrm{A}, \mathrm{b}}$ & $0.93 \pm 0.18^{B, C}$ & $1.16 \pm 0.18^{\mathrm{C}, \mathrm{d}}$ \\
\hline
\end{tabular}

Table 1. Mean surface roughness $(\mathrm{Ra}, \mu \mathrm{m})$ and standard deviations of zirconia specimens as a function of particle type and deposition duration. Same superscript capital letters indicate no significant difference in the same row, and small letters in the same column $(p<0.05)$

\begin{tabular}{|c|c|c|c|}
\hline & 5 seconds & 15 seconds & 30 seconds \\
\hline $30 \mu \mathrm{m} \mathrm{SiO}{ }_{2}$ & $8.91 \pm 0.23^{\mathrm{A}, \mathrm{a}}$ & $9.03 \pm 0.32^{\mathrm{A}, \mathrm{a}}$ & $9.11 \pm 0.15^{\mathrm{A}, \mathrm{a}}$ \\
\hline $50 \mu \mathrm{m} \mathrm{Al} \mathrm{O}_{3}$ & $10.14 \pm 0.37^{A, b}$ & $11.23 \pm 0.12^{A, b}$ & $14.22 \pm 0.08^{\mathrm{B}, \mathrm{b}}$ \\
\hline $110 \mu \mathrm{m} \mathrm{Al} \mathrm{O}_{3}$ & $10.41 \pm 0.24^{A, b}$ & $11.52 \pm 0.31^{A, b}$ & $15.63 \pm 0.34^{\mathrm{B}, \mathrm{C}}$ \\
\hline $250 \mu \mathrm{m} \mathrm{Al} \mathrm{O}_{3}$ & $11.43 \pm 0.27^{\mathrm{A}, \mathrm{C}}$ & $13.44 \pm 0.32^{\mathrm{B}, \mathrm{c}}$ & $16.43 \pm 0.33^{\mathrm{C}, \mathrm{d}}$ \\
\hline
\end{tabular}

Table 2. Relative amount of monoclinical phase (\%) according to $X R D$ measurements. Same superscript capital letters indicate no significant difference in the same row, and small letters in the same column $(p<0.05)$ 
Figures:
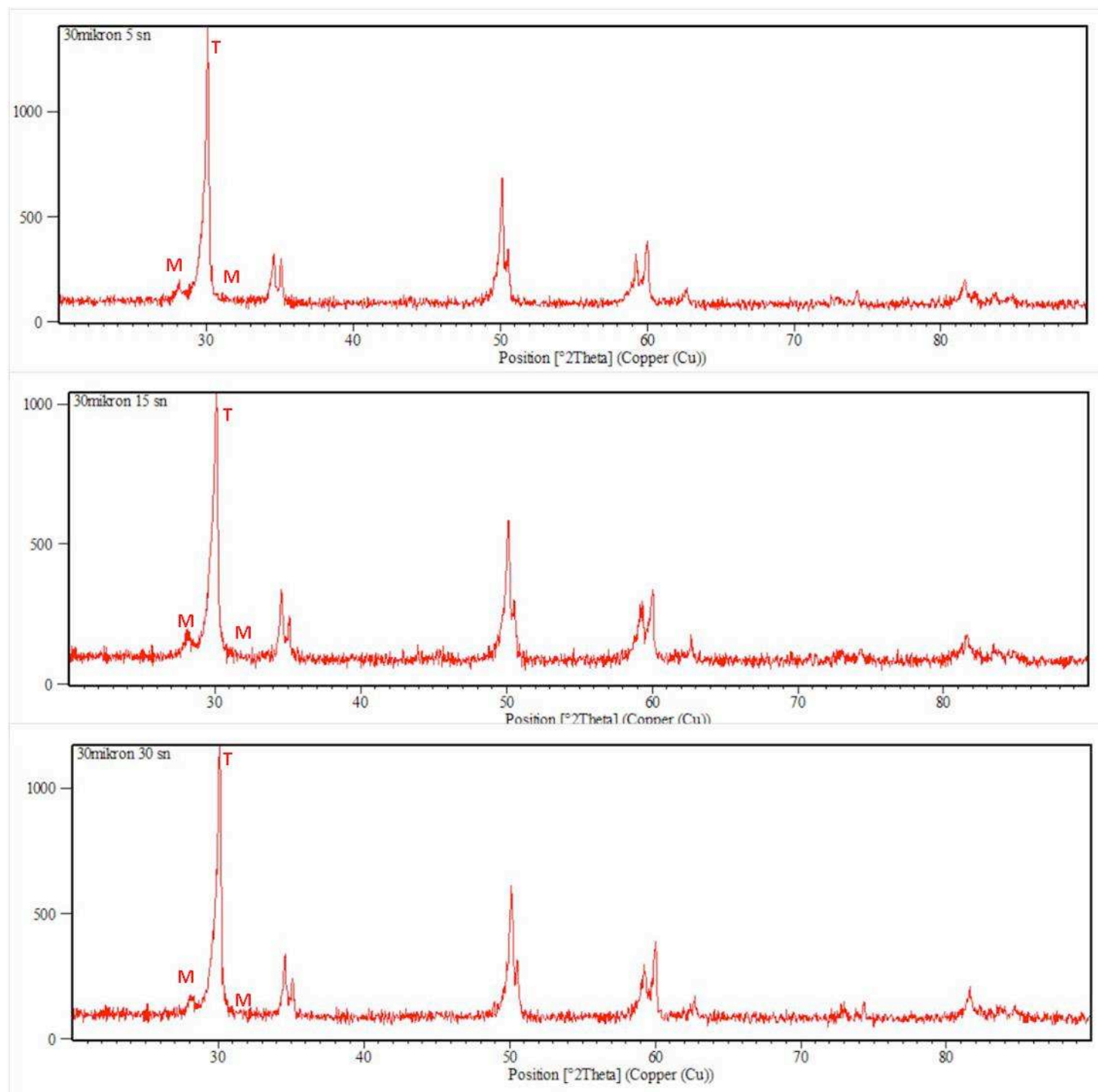

a) 

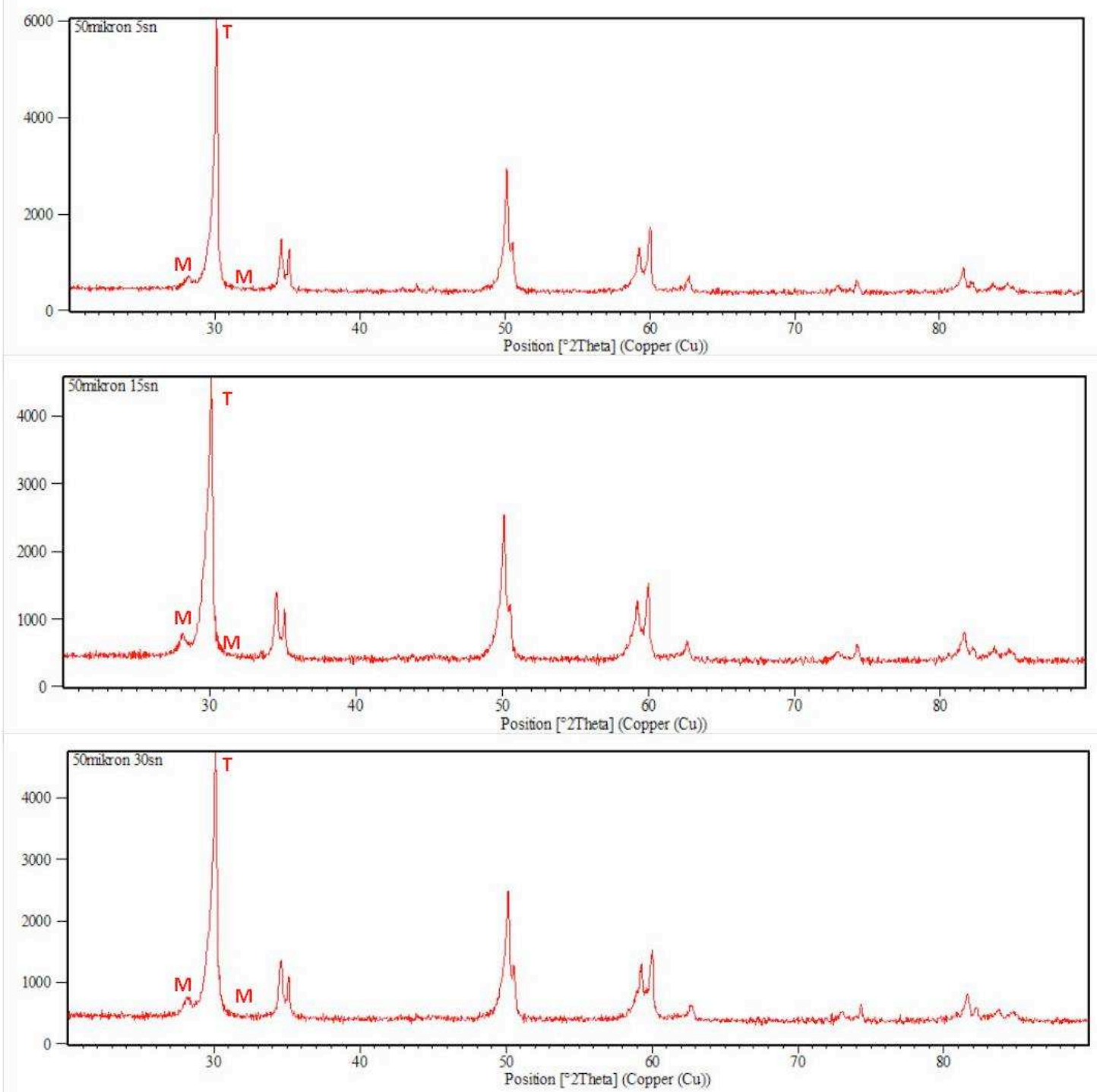

b) 

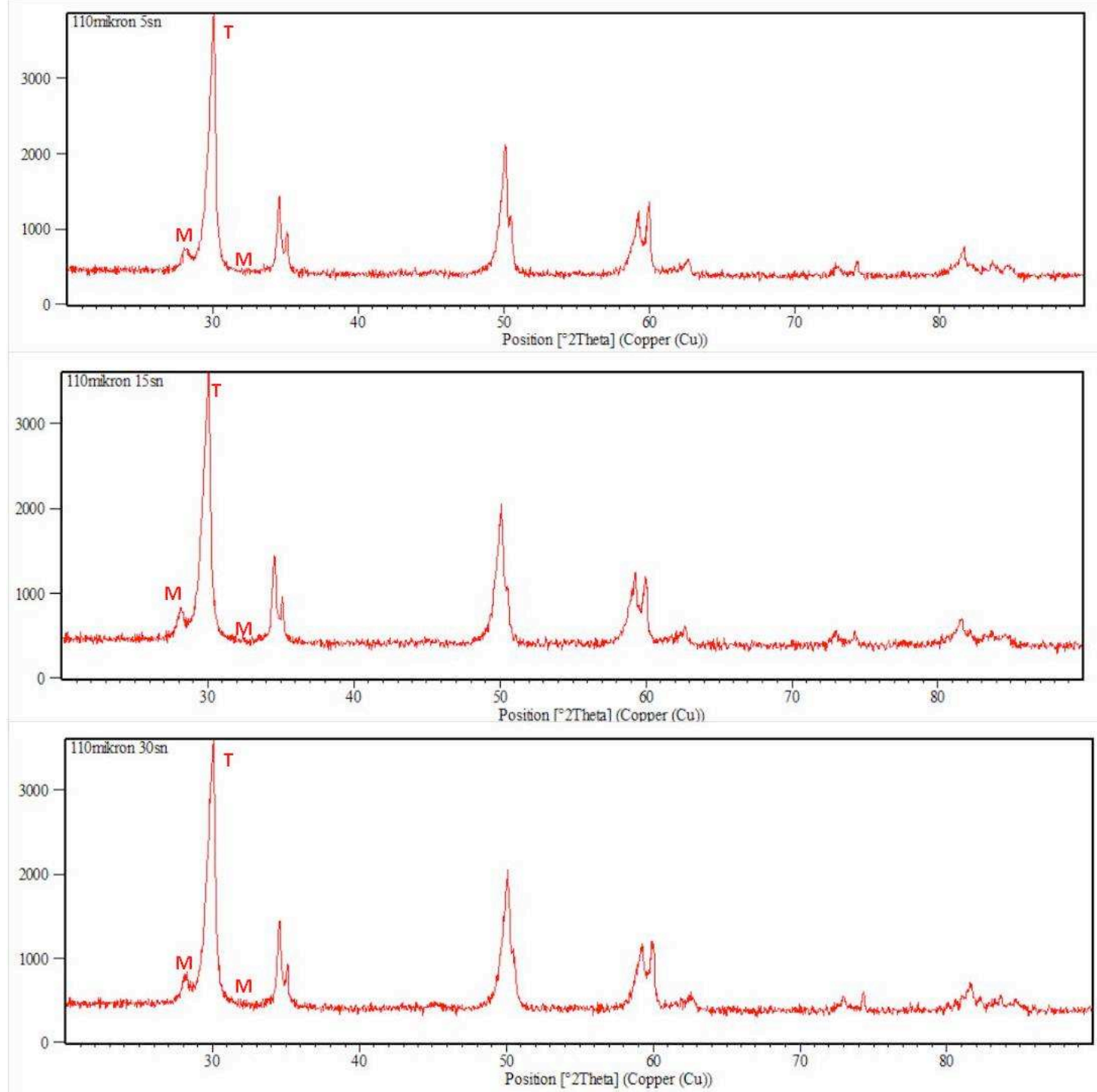

c) 

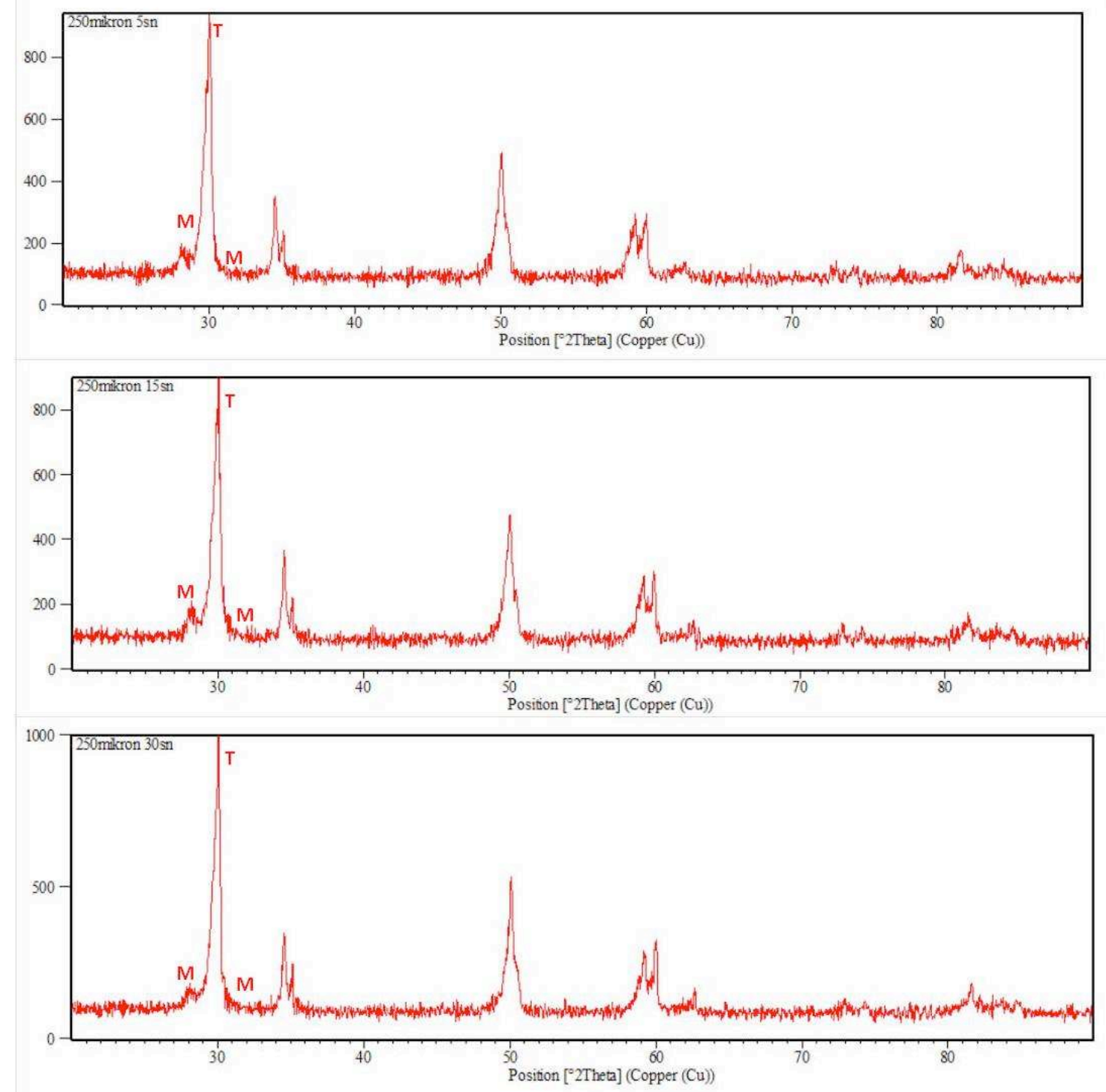

d)

Figs. 1a-d XRD diagrams of zirconia specimens after deposition of a) $30 \mu \mathrm{m} \mathrm{SiO}$, b) $50 \mu \mathrm{m} \mathrm{Al}_{2} \mathrm{O}_{3}$, c) $110 \mu \mathrm{m} \mathrm{Al}_{2} \mathrm{O}_{3}$ and d) $250 \mu \mathrm{m} \mathrm{Al} \mathrm{O}_{3}$ for 5,15 and 30 seconds. Note the differences in $\mathrm{T}$ and $\mathrm{M}$ peaks as the application duration changes. 

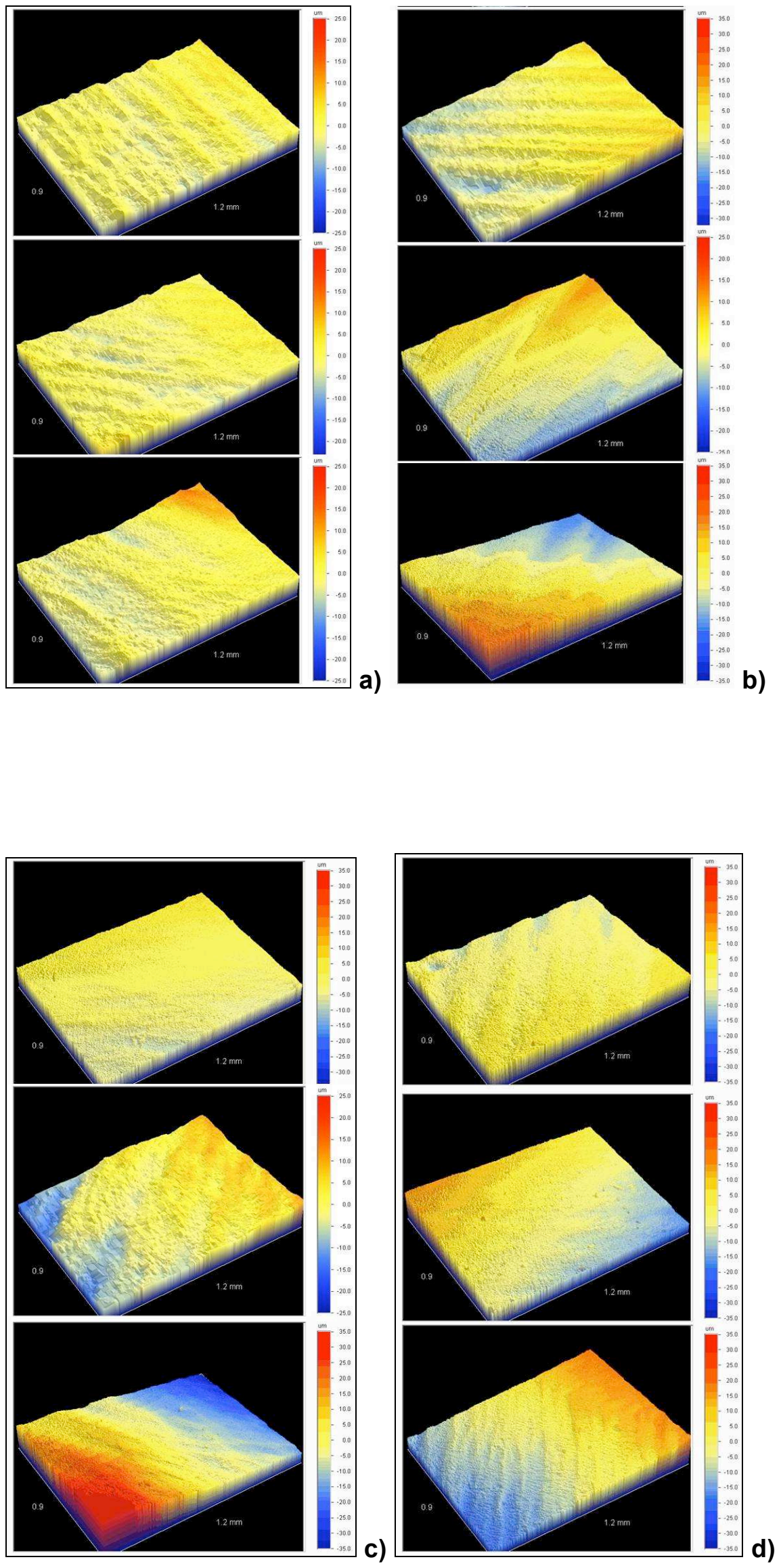

Figs. 2a-d 3D profilometry images of zirconia specimens after deposition of a) $30 \mu \mathrm{m} \mathrm{SiO}$, b) $50 \mu \mathrm{m} \mathrm{Al}_{2} \mathrm{O}_{3}$, c) 110 $\mu \mathrm{m} \mathrm{Al}_{2} \mathrm{O}_{3}$ and d) $250 \mu \mathrm{m} \mathrm{Al} \mathrm{O}_{3}$ for 5,15 and 30 seconds. Note that the hard-milling traces were not completely removed in all groups. 

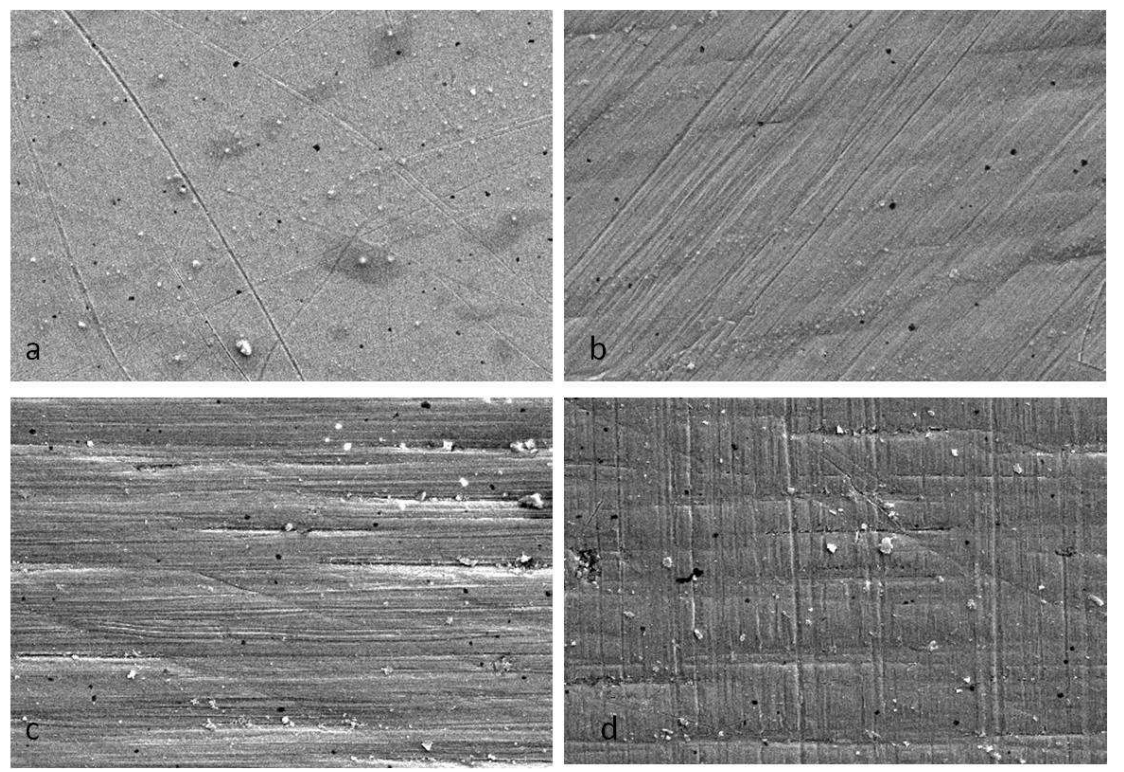

Figs. 3a-d SEM images (x700) of zirconia specimens after deposition of a) $30 \mu \mathrm{m} \mathrm{SiO} \mathbf{S}_{2}$, b) $\left.50 \mu \mathrm{m} \mathrm{Al}_{2} \mathrm{O}_{3}, \mathbf{c}\right) 110 \mu \mathrm{m}$ $\mathrm{Al}_{2} \mathrm{O}_{3}$ and d) $250 \mu \mathrm{m} \mathrm{Al} \mathrm{O}_{3}$ for 30 seconds. Note that the hard-milling traces were not completely removed in all groups. 